appropriately, consistently and noncollusively, rather than to react. It can, I believe, be both more effective and professionally more rewarding and could overcome the reluctance of psychiatrists to take responsibility for these neglected patients.

Kendell, R. E. (2002) The distinction between personality disorder and mental illness. British Journal of Psychiatry, 180, I10-115.

Livesley, J. W. (200I) Handbook of Personality Disorders. New York: Guilford Press.

Ryle, A. (1997) The structure and development of borderline personality disorder: a proposed model. British Journal of Psychiatry, 170, 82-87.

- \& Kerr, I. B. (2002) Introducing Cognitive Analytic Therapy: Principles and Practice. Chichester: J.Wiley \& Sons.

Trevarthen, C. (200I) Intrinsic motives for companionship in understanding: their origin, development and significance for infant mental health. Infant Mental Health Journal, 22, 95-131.

A. Ryle CPTS Munro Centre, Guy's Hospital, London SEI 3SS, UK

I would like to offer three comments on Kendell's useful conceptual exploration of personality disorder (Kendell, 2002). First, reduced life expectancy, which Kendell passes on to us, sceptically from Scadding, as a core, defining feature of disorder is implausible. As this criterion refers to aggregate data about a social group, not a claimed causal link about a particular individual, it prompts an odd conclusion. For example, both male gender and poverty predict (reduced) longevity. Does this mean that being male or poor are medical disorders? Such a medicalisation of material or existential disadvantage would surely stretch a metaphor very thinly.

Second, a categorical diagnostic approach (disordered/non-disordered) makes us a hostage to fortune when researching interventions. If we are obliged to ask the categorical question 'is personality disorder treatable?', it will produce a predictably ambiguous answer (Dolan \& Coid, 1993). From this flows an understandable ambivalence about the willingness to 'treat' among general psychiatrists (Cawthra \& Gibb, 1998) and even among some forensic psychiatrists (Cope, 1993). If we asked a different sort of question, such as, 'can we reduce the re-offending rates of sex offenders using this specific intervention', we might get a useful probabilistic answer about trying to change some people who habitually offend our moral order in a particular way. For example, it is cost-effective to offer psychological interventions (note: not 'treatment') to detained sex offenders as a group, even though risk prediction at the individual level remains problematic on release.

Third, the ambiguities Kendell correctly exposes about the relationship between personality disorder and mental illness also apply to the permeable boundary with normality. Common aspects of parliamentary life (e.g. sexual and financial 'sleaze' and the routine impression-management of politicians), some sport (e.g. boxing and hunting) and some private sexual activity (e.g. consensual sadomasochism) overlap strongly with DSM criteria for variants of 'dramatic' personality disorder. In my view, this points to the logical superiority of a dimensional over a categorical approach (Pilgrim, 2001).

Readers may correctly spot that this dimensional preference is predictable from a psychologist, which highlights that the 'nature' of 'personality disorder' is bound up with the constructs favoured by particular professional groups. However, Kendell, a psychiatrist, also argues that a dimensional view makes more sense (he calls them 'graded traits') - suggesting that a categorical approach has now failed us all, both scientifically and pragmatically. The category of personality disorder is not inherent to those who gain the label, but is a by-product of our professional discourse. A further indication of this point is that whether a detected child molester becomes a prisoner or a patient is a function of multi-party professional judgements. Thus, 'personality disorder' is socially negotiated - it does not exist 'out there' waiting to be discovered. If we go looking, we find 'it', in vast amounts, via circular psychiatric epidemiology (Kuller, 1999), particularly in prison populations. In my view we should abandon the concept of personality disorder altogether and appraise whether and how society (not just mental health professionals) can respond correctively to the wide range of role/rule violations it subsumes.

Cawthra, R. \& Gibb, R. (1998) Severe personality disorder - whose responsibility? British Journal of Psychiatry, 173, 8-10.

Cope, R. (1993) A survey of forensic psychiatrists' views of psychopathic disorder. Journal of Forensic Psychiatry, 4 215-235.

Dolan, B. \& Coid, J. (1993) Psychopathic and Antisocia Personality Disorders: Treatment and Research Issues. London: Gaskell.
Kendell, R. E. (2002) The distinction between personality disorder and mental illness. British Journal of Psychiatry, 180, II0-115.

Kuller, L. (1999) Circular epidemiology. American Journal of Epidemiology, 150, 897-903.

Pilgrim, D. (200I) Disordered personalities and disordered concepts. Journal of Mental Health, 10 253-265.

D. Pilgrim Guild Community Healthcare NHS Trust, Clinical Psychology Services, Ribbleton Hospital, Miller Road, Preston PR2 6LS, UK

Author's reply: Dr Bennett's, Dr Ryle's and Professor Pilgrim's letters raise several very different issues, which makes it impossible for me to respond to, or even comment upon, more than a few of them.

Dr Bennett's argument that the concept of mental illness assumes an 'abnormality of higher mental function' and that personality disorders 'lack good-quality evidence of altered higher mental function' is essentially the same as Aubrey Lewis's contention that mental illness involves an 'evident disturbance of part-function as well as of general efficiency', and that 'until the category (of psychopathic personality) is ... shown to be characterised by specified abnormality of psychological functions, it will not be possible to consider those who fall within it to be unhealthy' (Lewis, 1953). Lewis's views had a considerable influence on my generation of psychiatrists but now, 50 years on, the limitations of this criterion for distinguishing between personality disorder and mental illness are increasingly apparent, mainly because of the evidence that some personality disorders and some mental disorders share the same genetic diathesis, and are sometimes amenable to the same treatments. As a result, confusion reigns. The affective personality disorder of ICD-9 has been replaced by two new mental disorders, cyclothymia and dysthymia, in ICD-10; schizotypal disorder is classed as a personality disorder in DSM-IV but with schizophrenia and delusional disorders in ICD-10; and the authors of DSM-IV wonder whether avoidant personality disorder may simply be an 'alternative conceptualisation' of generalised social phobia.

Dr Ryle argues that the behaviour of people identified as having 'borderline personality disorders' is understandable in the light of their childhood experience 
and is amenable to cognitive-analytic therapy. This may indeed be so. Unfortunately, from my perspective, it does not solve the problem, if only because the psychoanalytic concept of borderline personality only embraces a small part of personality disorder as a whole. Dr Ryle also asserts that 'the need is . . . for an understanding of persons' and has no sympathy with my (and, I presume, Dr Bennett's) interest in 'underlying cerebral mechanisms'. Many psychotherapists would agree with him. But I still have to insist that we must agree what is implied by the term mental illness before we can decide whether personality disorders are mental illnesses or not, and that the forensic issues involved mean that this is not a trivial issue.

Professor Pilgrim asks, perhaps with tongue in cheek, whether Scadding's definition of disease (not mental disorder) implies that being male or poor are diseases. The answer in both cases is, of course, no. Scadding's definition refers explicitly to variation 'from the norm for the species', so the reference group for a putative male disease would be the life expectancy of other males. Likewise, poverty is a handicap imposed by the environment which may increase the risk of several diseases, and thereby reduce life expectancy, but is not itself a disease. For similar reasons, living in a zoo rather than a natural habitat is a disadvantageous environment for many wild animals, not a disease of wild animals, despite the implications for longevity. More importantly, Professor Pilgrim refers to the 'logical superiority of a dimensional over a categorical approach' to the classification of personality disorders and chides psychiatrists for what he regards as their inappropriate attachment to categories. I would argue that the relative merits of categorical and dimensional classifications is an empirical issue rather than a matter of logic, and that their relative advantages and disadvantages may vary with the purpose for which the classification is to be used. In fact, it is explicitly recognised in ICD-10 that personality disorders 'represent either extreme or significant deviations from the way the average individual ... perceives, thinks, feels, and particularly relates to others'. It is also on the cards that in DSM-V the American Psychiatric Association will replace its present categorical classification of personality disorders with a set of dimensions.
Lewis, A. (1953) Health as a social concept. British Journal of Sociology, 4, 109-124.

R. E. Kendell 3 West Castle Road, Edinburgh EHIO 5AT, UK

\section{Patient adherence with antidepressant treatment}

Reading the article by Pampallona et al (2002) on patient adherence in the treatment of depression, I sought in vain for any overt indication that mental health service users themselves were routinely being asked for their views, either by practitioners or by researchers. 'Patient education' and 'education of the patient's family' may well be interventions worthy of study, but methodologies used to look at this problem appear to fail to take account of what mental health professionals can learn from patients, families and carers.

A recent survey of over 2600 service users and carers, undertaken by the National Schizophrenia Fellowship, the Manic Depression Fellowship and Mind (Hogman \& Sandamas, 2001) found that $27 \%$ had not had their medicine discussed with them, $46 \%$ had not received any written information about the possible side-effects of medicine, and a startling $62 \%$ had never been offered a choice of medicine. The survey concluded that, 'Positive outcomes are increased if people are informed about their choices, allowed to choose and given their choice'. This message seems slowly to be seeping into the consciousness of our political masters, with Hazel Blears, Parliamentary Under Secretary of State for Health, actively promoting increased informed choice for patients, including treating patients as partners in care, and giving them the confidence to take control of their own treatment. When the medical profession as a whole can embrace this in respect of patients with a mental illness then, unlike Pampallona and his colleagues, we may be some way nearer to finding out what interventions work successfully.

Blears, H. (2002) Further Steps to Patient-Centred NHS. Press release, Department of Health, 29 January 2002. http: / /tap.ccta.gov.uk/doh/intpress.nsf/page/ 2002-0046?OpenDocument

Hogman, G. \& Sandamas, G. (200I) A Question of Choice. London: National Schizophrenia Fellowship.

Pampallona, S., Bollini, P., Tibaldi, G., et al (2002) Patient adherence in the treatment of depression. British Journal of Psychiatry, 180, 104-109.

S. Lawton-Smith MACA (Mental After Care Association), 25 Bedford Square, London WCIB 3HW, UK
In an interesting article, Pampallona et al (2002) reviewed the literature concerning patient adherence in the treatment of depression. The outcome of most studies revealed that interventions to improve adherence tend to be successful in most cases, although it is not completely clear which interventions may be the most helpful.

In our view, the most important goal in trying to enhance adherence is to improve treatment outcome. Pampallona et al stated that 'the important relationship between adherence and outcome of treatment has been evaluated only in one study'.

When we reviewed the articles that Pampallona et al included in their article, however, we identified at least four studies that addressed the relationship between adherence and treatment outcome.

Katon et al (1995, 1996) demonstrated that multifaceted interventions improved adherence to antidepressant regimens in patients with major and with minor depression. The interventions resulted in more favourable outcomes in patients with major, but not minor, depression. In a more recent study of the same group (Katon et al, 1999) patients in the intervention group also had significantly better adherence to antidepressive medication and showed a significantly greater decrease in severity of depressive symptoms over time and were more likely to have fully recovered during follow-up at 3 and 6 months. Peveler et al (1999) found that counselling about drug treatment significantly improved adherence. Clinical benefit, however, was seen only in patients with major depressive disorder receiving doses $\geqslant 75 \mathrm{mg}$ of a tricyclic antidepressant.

These findings provide evidence that interventions can enhance adherence and can increase the response rate in patients with major depression who are treated with an adequate dosage of an antidepressant agent. With respect to minor depression results are less convincing.

Katon, W., Von Korff, M., Lin, E., et al (1995)

Collaborative management to achieve treatment guidelines. Impact on depression in primary care. JAMA, 273, $1026-103$

, Robinson, P., Von Korff, M., et al (1996) A multifaceted intervention to improve treatment of depression in primary care. Archives of General Psychiatry, 53, 924-932.

_ Von Korff, M., Lin, E., et al (1999) Stepped collaborative care for primary care patients with resistant symptoms of depression. Archives of General Psychiatry, 56, II09-1115. 